\title{
EL NO-DO NO BAILÓ A RITMO DE ROCK
}

Magí CRUSELLS VALETA

Universitat de Barcelona crusells@ub.edu

\section{THE NO-DO NOT DANCED TO THE ROCK RHYTHM}

Resumen: A través de este artículo se realiza un análisis de las apariciones en NO-DO entre 1964 y 1966 de tres de los conjuntos británicos emblemáticos de la década de los 60: los Beatles, los Rolling Stones y los Animals para demostrar el control y la censura que NO-DO realizó sobre sus apariciones en los noticiarios emitidos en los cines de toda España.

Abstract: In this paper, it is carried out an analysis of the different appearances in NO-DO between 1964 and 1966 of three of the most emblematic British bands in the sixties: The Beatles, The Rolling Stones and the Animals to demonstrate the control and the censorship that NO-DO was subject in their appearances in the news broadcasts projected in all Spanish cinemas.

Palabras clave: NO-DO. Música. Rock. Los Beatles

Music. Rock. The Beatles 


\section{Los principales conjuntos musicales ingleses según NO-DO}

NO-DO mostró la evolución de la sociedad mundial durante los años en que estuvo en funcionamiento. Conviene recordar su eslogan: "el mundo entero al alcance de todos los españoles". Durante el periodo franquista lo hizo a través de la visión de los principios del llamado Movimiento, pretendiendo ser el único cauce audiovisual de participación en la vida pública española. Incluso aparecían noticias que, en un principio, no tendrían que comulgar con el estado creado por Franco, pero en algunas ocasiones era para infravalorarlas y otras para ridiculizarlas. El noticiario incluyó algunos reportajes dedicados a grupos musicales extranjeros. Eran retratados de forma negativa por no ser del agrado de las autoridades franquistas.

La música moderna no era sólo un instrumento donde se refugiaban muchos de los jóvenes españoles de los años sesenta, sino que servía para que comulgasen con unos mismos gustos y aficiones. Muchos de ellos respiraron libertad, oponiéndose a unas normas rígidas que comenzaban a estar caducas (Valiño: 2012) Las autoridades franquistas consideraban la música rock y pop como poco saludable para la juventud española. Por ejemplo, la música de los Beatles -el grupo más popular de la década de los 60- era clasificada como ruidosa y estridente, mientras que su aspecto físico -sobre todo el pelo largo- como un producto de la decadencia de Occidente. A pesar de todo, la música rock y pop llegó a España por su propio impulso.

La música es un arte popular de primer orden. Las letras y los ritmos del pop y del rock tuvieron calaron desde sus inicios entre la población, en especial la juventud. Por esta razón, se intentó ejercer sobre ella un control que pasó por una censura llegó a censurar, manipular o prohibir ciertos artistas y sus obras.

A continuación, comentaremos las apariciones en NO-DO entre 1964 y 1966 de tres de los conjuntos británicos emblemáticos de la década de los 60: los Beatles, los Rolling Stones y los Animals entre 1964 y 1966. Escribo entre cursiva el título incluido en el programa, entre paréntesis la fecha del estreno y diversos comentarios despectivos que se pueden escuchar:

- 1102 C (17.02.1964). Los “Beatles” y sus imitadores. La última novedad en París. El grupo es descrito como "músicos y cantantes excéntricos ingleses" que "desencadenan con su atuendo y sus números explosivos el delirio de muchachos y muchachas. Además del ruido, las melenas son su distintivo".

-1103 B (24.02.1964). Los “Beatles” en Nueva York. Una “invasión” simpática.

La reacción de las fans que están en frente del Hotel Plaza es narrada así: "Estas jovencitas demuestran su simpatía por los extravagantes ingleses que acaban de invadir musicalmente su territorio".

- 1123 B (13.07.1964). Los “Beatles” en Holanda. Recibimiento multitudinario en el aeropuerto de Amsterdam. Mientras el grupo recorre en una embarcación uno de los canales de la ciudad se producen "escenas de histerismo popular y contagioso" por parte de los jóvenes que chillan y saludan a sus ídolos. Incluso uno de ellos de lanza al agua, poniéndose en remojo, con tal de acercarse a ellos:

- 1132 A (14.09.1964). “Los Animales” cantores, huéspedes de Nueva York. Admiración e histerismo al paso por Times Square. Según el locutor, el grupo "es la última hornada de desmelenados ingleses del rock and roll, continuadores de la escuela de los Escarabajos", en clara alusión a los Beatles.

- 1149 A (11.01.1965). Los "Rolling Stones" nueva promoción de los

"Escarabajos". Ruidosa recepción de Bruselas. "El excéntrico quinteto", 
así es definido por el locutor, "que con sus actitudes y pelucas proporcionan pretexto para el griterío a pleno pulmón y algunas escenas de histerismo colectivo. La policía de la capital belga está a la expectativa para que no se produzcan mayores incidentes".

- 1175 B (12.07.1965). "Los Beatles” en Madrid. Aspectos de su estancia y actuación. Por su importancia, esta noticia se comenta más adelante.

- 1176 A (19.07.1965). Reportaje sobre la montera. Se incluyen cuatro segundos de la llegada del conjunto musical al aeropuerto de Barcelona el 3 de julio donde "aún queda un tipo de montera turística para que los Beatles recuerden su viaje por España”.

- 1204 A(31.01, 1966). Músicos “ye-yé” tras el Telón de Acero. "Los Animales” se presentan al público de Varsovia. Según el narrador, la juventud de esta ciudad "recurre a los mismos excesos que la de Occidente cuando siente la necesidad de divertirse", mientras se les observa chillando y bailando. Esta actuación, celebrada el 16 de noviembre de 1965 en la sala Kongresowa, fue muy importante porque representó el primer concierto de unos de los grupos ingleses más importantes en aquellos años en un país de la órbita soviética. El 13 de abril de 1967 tocarían en el mismo lugar los Rolling Stones. En España no lo hicieron hasta el 11 de junio de 1976 en la plaza de toros Monumental de Barcelona, casi ocho meses más tarde de la muerte del dictador.

Finalizada la Guerra Civil española, Francisco Franco residió en Burgos hasta su despedida el 18 de octubre de 1939, trasladándose al castillo de Viñuelas -en la carretera de Madrid a Colmenar Viejo- hasta el 15 de marzo de 1940, fecha en que terminó de acondicionarse el Palacio Real de El Pardo, seriamente dañado por el alojamiento de las Brigadas Internacionales, que tuvieron en él su Cuartel General durante la citada Guerra Civil. Entre las obras de acondicionamiento para ser residencia oficial de Franco, estuvo el convertir el teatro, que construyera Carlos III y remodelara Carlos IV, en la "sala de cine". Entre 1946 y 1975, Franco visionó cerca de 2.000 películas en el Palacio de El Pardo: en ocasiones dos largometrajes comerciales por semana, junto a varios números del noticiario NO-DO y otros documentales (Caparrós; Crusells, 2018). No tenemos información para saber quién hacía la selección de los números de NO-DO que se incluían en las sesiones cinematográficas de El Pardo, si Franco o su esposa, algún miembro de la Casa Civil de Su Excelencia el Jefe del Estado o del propio NO-DO. Ignoramos la reacción de Franco al ver y escuchar a los Beatles, los Rolling Stones o los Animals a través del NO-DO. Es muy difícil que Franco disfrutara con esta clase de música ya que en una ocasión le llegó a decir al pianista José Tordesillas que "yo, la verdad, a veces oigo la radio y ese tipo de música me crispa" (Baón, 1975: 94).

\section{NO-DO y la estancia de los Beatles en España}

Durante el corto espacio de tiempo que el grupo musical estuvo en España -de media tarde del 1 de julio hasta la mañana del día 4-, las únicas cámaras cinematográficas que lo filmaron ampliamente fueron las de NO-DO. Las imágenes de la capital española fueron rodadas bajo la dirección de Francesc Betriu y Pedro Costa, estudiantes por aquel entonces de la Escuela Oficial de Cinematografía, con la ayuda de José Pader y Juan Manuel de la Chica, dos operadores de NO-DO. Había dos equipos, uno de sonido y otro para la imagen, ambos sincronizados. Su intención era realizar un documental titulado Los Beatles en Madrid, que nunca llegó a montarse ni a ser editado, ya que no fue autorizado. Las escenas de la Ciudad Condal fueron rodadas, sin sonido, por Juan Amorós y Blas Martí, dos operadores de NO-DO. 
Finalmente, en el noticiario de NO-DO número 1176 B, estrenado el 12 de julio de 1965, solo se incluyeron alrededor de tres minutos de imágenes de la estancia de los Beatles en Madrid, con un tono despectivo y negativo, y ninguna de su paso por Barcelona.

En 1994, cuando escribí junto a mi buen amigo Alejandro Iranzo el libro The Beatles. Una filmografía musical entrevistamos a Paco Betriu y a Pedro Costa. El primero piensa: "Manuel Fraga Iribarne fue el verdadero culpable que no se realizara el documental Los Beatles en Madrid ya que él estaba al frente del Ministerio. Augusto García Viñolas, director por aquel entonces de NO-DO, fue quien la ejecutó. No les dieron ninguna explicación, pero estaba claro que no les gustaba la imagen que los Beatles podían ofrecer a la juventud española. Tanto a Pedro Costa como a mí, simplemente nos dijeron que nos podíamos ir a nuestra casa, porque el documental no se montaba. Aun así, recuerdo que cobramos cinco mil pesetas cada uno". Por su parte, Costa recordaba que "una vez filmado todo el material de Madrid, García Viñolas se enteró del proyecto y prohibió el montaje porque consideró que habíamos estado malgastando material y perdiendo el tiempo con unos ingleses degenerados, en vez de filmar cosas más provechosas para el régimen como, por ejemplo, el plan agrícola de no sé dónde. Eso sí, recuerdo que nos pagaron por el trabajo efectuado".

Afortunadamente, parte de las imágenes rodadas por NO-DO se guardan en la actualidad en la Filmoteca Española gracias al buen hacer de Jorge Palacio, quien conservaba todo el material que llegaba a sus manos. El material está en bruto, es decir, no está montado y, por lo tanto, permanece desordenado. De la estancia madrileña, existen dos rollos con una duración de casi 22 minutos, mientras que de la visita a Barcelona solo se guarda un rollo de alrededor de 11 minutos. Entre el material que proporciona una valiosa información está un primer plano del cartel The Beatles. Nota de precios, situado en el exterior de la plaza de toros de Las Ventas, que proporciona información sobre el precio de las localidades que iban desde las 400 pesetas -Sillas de pista. Sector Centro. Filas 1 a 4- hasta las 75 - Sillas de pista. Sector E y J y Filas y balcones.

La bobina de sonido grabada en Madrid está perdida. Pedro Costa recuerda que a NODO se devolvió el material cinematográfico, "pero la cinta magnetofónica me la quedé yo. Lo que no sé es si la volví a grabar por encima o la lancé a la basura inconscientemente a principios de los 90, cuando hice limpieza en mi casa. Lo que sí sé es que en la actualidad no la tengo."

Sin embargo, del material conservado de NO-DO se pueden descifrar algunas de las canciones interpretadas en sus conciertos españoles. De la bobina de Madrid se recogen momentos de Twist and shout, She's a woman, I'm a loser, Can't buy me love, Baby's in black, I wanna be your man, I feel fine, o Ticket to ride. De la Barcelona hay fragmentos de Twist and shout, She's a woman-George Harrison deja un instante de tocar porque tiene un problema con su guitarra-, I'm a loser, Can't buy me love, I wanna be your man, Ticket to ride y Long tall Sally.

Francesc Betriu y Pedro Costa rodaron, según su testimonio, más de una hora de metraje. La edición de NO-DO número 1175 B, con una duración de 9 minutos y 45 segundos, incluyó la noticia "Los Beatles en Madrid" de casi tres minutos. Comento a continuación tanto las imágenes como la narración del locutor, José Hernández Franch, indicando entre paréntesis la duración de la secuencia correspondiente, con la finalidad de constatar la adulteración que los dirigentes de NO-DO realizaron del proyecto ideado por Francesc Betriu y Pedro Costa, que deseaban reflejar la incidencia sociológica de la llegada y del concierto:

Voz en off: También llegan a Madrid los Beatles, conjunto musical británico compuesto por cuatro intérpretes, cuyas efigies andan ya dibujadas en camisas como ésta (0: 00.0: 12). 
John Lennon, Paul McCartney, George Harrison y Ringo Starr bajan por la escalerilla tras abandonar un avión de la compañía Air France. Lennon parece que esté masticando un chicle. A excepción de George, todos saludan con la mano. Esta escena está filmada desde la pista en un plano contrapicado. La referencia del locutor a un dibujo de una camisa alude a un plano medio de un joven, vestido con una camisa y gorra marinera. En la parte trasera de la primera prenda se distinguen las caricaturas de Harrison y Ringo y la inscripción "The Beatles", mientras que en la gorra aparece escrito el nombre "Cucho". Después se contempla en un plano general al grupo de Liverpool caminando por la pista de aterrizaje y saludando -menos George Harrison- a los fans que están en una terraza:

Voz en off: La recepción que se les hace en Madrid no es apoteósica, pero en el aeropuerto se ha concentrado una juventud curiosa y alegre (0: 13-0: 19).

En esta secuencia aparecen unas chicas que están en el exterior del aeropuerto, pero apenas pueden distinguirse sus rostros porque unas se los tapan con manos o brazos, y otras dan la espalda a la cámara. De todas formas, se puede distinguir a la futura actriz Marta Fernández Muro:

Voz en off: Hay muchos fotógrafos y operadores en la rueda de prensa que se celebra en el hotel donde se hospedan. Los objetivos apuntan principalmente sobre los "tocados capilares" (0: 20-0: 46).

Hay una secuencia de la sala de prensa protagonizada por los fotógrafos con sus máquinas. Posteriormente se filma un sofá vacío. En el siguiente plano Ringo Starr y Paul McCartney aparecen sentados en el sofá, en tanto que John Lennon y George Harrison están situados detrás, de pie, posando para las cámaras de los reporteros. Después Ringo firma un autógrafo. Acto seguido responden a las preguntas de los periodistas, algunos de los cuales están a una escasa distancia del grupo y muy juntos. Hay una toma de Ringo bebiendo de un vaso. Luego se observa a Paul McCartney con un clavel en la boca, sacándoselo con la mano izquierda mientras Ringo le habla a él y a George Harrison. Destaca entre el grupo de periodistas allí congregados el crítico Hugo Ferrer:

Voz en off: En Madrid se les depara también la ocasión de firmar con sus nombres en los toneles de vino de Jerez (0: 47-0: 53).

Se aprecia un plano medio de John Lennon firmando en un tonel con una tiza blanca. En otro plano medio George Harrison y Ringo Starr hacen lo mismo. Los toneles de Harrison y Ringo están a la altura de su rostro, pero Lennon tiene que elevar el brazo derecho porque el suyo está por encima de él. En un momento determinado aparece en pantalla Manolo Alcalá, reportero del periódico Pueblo:

Voz en off: Hacen ensayos con la venencia y, para ser la primera vez, no está del todo mal. Y ahora la lección del profesional (0: 54-1: 14).

Bajo la atenta mirada de Ringo Starr, el escanciador y una de las hermanas Hurtado, John Lennon verte una copa de jerez que sujeta con la mano izquierda -a la izquierda de la imagen figura Francesc Betriu-. Luego lo hace el copero, sosteniendo con una mano varias copas. Al retirarse hacia atrás, salpica a Ringo y este se lleva su mano derecha a la cara para secarse las gotas. En otro plano se observa a McCartney aplaudir al echador, mientras que Betriu acerca un micrófono a Lennon, quien sonríe por el espectáculo que acaba de presenciar: 
Voz en off: Catan con gusto el caldo español que se ha impuesto en el mundo con el nombre de Sherry (1: 15-1: 23).

Esta secuencia empieza con un plano medio de Harrison y Ringo bebiendo jerez. Después se observa a Lennon y a McCartney. Este último, al ingerir la bebida alcohólica, guiña su ojo izquierdo a la cámara. Para finalizar, hay un primer plano que, describiendo un zoom, se acerca a un tonel donde aparece en tiza la inscripción "The Beatles":

Voz en off: La actuación musical está anunciada en la plaza de toros, donde salta a la vista que no hay un lleno (1:24-1: 35).

Se contempla el recinto taurino con un cuarto de entrada. Ello se debía a que las actuaciones de los teloneros, previstas a las 8: 30 h, aún no habían comenzado -en una panorámica aérea de los tendidos, tomada desde la pista, se ve que todavía el sol ilumina el cielo-. Aparecen un chico y una chica dirigiéndose a su localidad, ubicada en una grada, para sentarse:

Voz en off: Junto al bullidor elemento joven hay familias tranquilas. Y señores con barba, representantes del servicio doméstico. Muchachas nerviosas de las llamadas "fans"... Y, en el estribo de la barrera, la familia completa con el nene (1: 36-1: 56).

Estos comentarios hacen referencia a diversas imágenes: un chico joven está charlando con un hombre de unos sesenta años y una mujer de unos cuarenta, todos ellos sentados en las gradas; un hombre calvo con barba se halla en la pista y delante de él está sentado un agente de la Policía Armada; una mujer que trabaja en uno de los servicios de la plaza se encuentra en las gradas, al lado de una boca de entrada donde está situado un policía; una chica con gafas aparece mordiéndose las uñas, de pie en la pista; y dos parejas con un perro, un niño y un bebé sentados en el estribo de la barrera. Al principio la criatura está en un cochecito, pero en una secuencia posterior reposa en los brazos de una de las mujeres:

Voz en off: No faltan espectadoras impacientes que ya marcan el ritmo antes de que aparezcan los Beatles en el escenario (1: 57-2: 03).

Se ven tres chicas bailando en las gradas. Dos de ellas acaban de levantarse de sus asientos para moverse con mayor comodidad. Las personas que están a su alrededor sonríen ante la actitud de las jóvenes. Ellas bailan durante la actuación de algunos de los grupos o cantantes que actuaron en Las Ventas y no antes porque, de no ser así, no se moverían de este modo. Lo que sucede es que el locutor que narra la escena en cuestión trata de darle una unidad temporal a todas las imágenes:

Voz en off: ¡Por fin! Salen los melenudos al tablado. Alguno lleva sombrero ancho; es una concesión al ambiente. He aquí un fragmento de su actuación y algunas fases de la reacción del público (2: 04-2: 43).

John Lennon -con sombrero cordobés-, Ringo Starr, Paul McCartney y George Harrison salen al escenario. Lennon y McCartney son los únicos que saludan al público. Los amplificadores son comprobados por Harrison y Lennon. Hay una breve secuencia de una mujer que sigue el ritmo musical moviendo los brazos. Un primer plano del escenario permite ver a John Lennon -que toca una guitarra acústica Gibson- y a Paul McCartney cantando un tema a dúo en un mismo micrófono. Posiblemente se trate de Ticket to ride. 
En los tendidos, un hombre, de unos cuarenta años, está bailando de pie y una chica se agarra a unas barras. Figura después un plano medio de McCartney cantando. Hasta este momento se escuchaba como música de fondo un tema instrumental en el que predominaba la guitarra solista, que nada tiene que ver con los Beatles.

A partir del momento en que el locutor comenta "he aquí un fragmento de su actuación y algunas fases de la reacción del público", hasta el final, se oye la canción Yes it is. Este tema había sido grabado el 16 de febrero de 1965, en los estudios EMI, en Londres, publicándose como cara B del disco sencillo "Ticket to ride". Este disco fue editado en España poco antes de sus actuaciones en Madrid y Barcelona, el 10 de junio -en Inglaterra lo había sido el 9 de abril-. La versión que se oye de Yes it is es el tema oficial aparecido en el single. Dicha balada nunca fue interpretada por el grupo ni en Madrid ni en ningún concierto en vivo a lo largo de su carrera. En determinados momentos se pueden oír unos chillidos de fans que están grabados sobre la canción.

Aparecen cuatro chicas en las gradas de pie. Una de ellas agita su mano y dos gritan. Sigue un plano medio de John Lennon tocando su guitarra rítmica. En los tendidos cinco jóvenes -cuatro chicos y una chica- bailan. Figura después un primer plano que encuadra la guitarra de Harrison y el bajo de McCartney, viéndose después a estos dos miembros del grupo haciendo coros en un micrófono. En la pista, un chico se levanta y agita su chaqueta. Se enlazan luego varios primeros planos de Ringo tocando la batería. Una niña de las primeras filas observa con unos prismáticos el escenario y una adolescente se tira de los cabellos:

Voz en off: Los Beatles pasaron por Madrid sin demasiada pena ni demasiada gloria (2: 44-2: 50).

Desde el ángulo izquierdo del escenario, la cámara recoge una de las reverencias que el grupo solía hacer entre canción y canción. Detrás de la batería de Ringo existe un decorado, semejante a un biombo, compuesto por tres piezas unidas entre sí. En los extremos del mismo están dibujadas unas guitarras eléctricas.

La voz en off de un noticiario asume la misión del narrador. A su vez, la imagen muestra aquello que el texto dice. En este caso, la alocución del narrador va desde la descripción bruta del suceso -por ejemplo, cuando al principio se comenta la llegada al aeropuertohasta la transmisión de una ideología -cuando los Beatles son llamados despectivamente "melenudos"-. El papel del narrador es muy importante, porque a través de su discurso se le imprime a este un tono determinado. La música instrumental de fondo produce el efecto de continuidad, pues sin ella las imágenes se empobrecerían, ya que abundarían los silencios. A lo largo de todo el noticiario destacan los planos descriptivos.

Parte del metraje rodado por Francesc Betriu, Pedro Costa Juan Amorós y Blas Martí se recuperó en el documental ¡Qué vienen los Beatles!, dirigido por el propio Pedro Costa en 1995 para RTVE.

\section{Bibliografía}

BAÓN, Rogelio (1975): La cara humana de un Caudillo. Editorial San Martín. Madrid, p. 94.

CAPARRÓS, José María; CRUSELLS, Magí (2018): Las películas que vio Franco (y que no todos pudieron disfrutar). Cine en El pardo, 1946-1975. Cátedra. Madrid.

CRUSELLS, Magí; IRANZO, Alejandro (1995): The Beatles. Una filmografía musical. Royal Books. Barcelona.

VALIÑO, Xavier (2012): Veneno en dosis camufladas. La censura en los discos de pop-rock durante el franquismo. Milenio. Lleida. 